Research paper

\title{
Simulation model for the transient process behaviour of solar aluminium recycling in a rotary kiln
}

\author{
Spiridon O. Alexopoulos a , Jürgen Dersch ${ }^{\mathrm{b}}$, Martin Roeb ${ }^{\mathrm{b},}{ }^{*}$, Robert Pitz-Paal ${ }^{\mathrm{b}}$ \\ a Solar-Institut Jülich, FH Aachen, Heinrich-Mußmann-Str. 5, 52428 Jülich, Germany

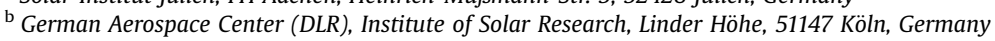

\section{H I G H L I G H T S}

- Transient model of solar aluminium recycling plant has been developed and validated.

- Transient behaviour of a solar rotary kiln smelting furnace has been simulated.

- A case study for a stand-alone plant operated at El Paso, Texas was performed.

- Simulation provided an overall plant efficiency of $52 \%$.

- A maximum daily efficiency of $72 \%$ was found if solar conditions are very good.

\section{A R T I C L E I N F O}

\section{Article history:}

Received 17 July 2014

Accepted 3 January 2015

Available online 12 January 2015

\section{Keywords:}

Aluminium

Melting

Recycling

Solar

Rotary kiln

\begin{abstract}
A B S T R A C T
The German Aerospace Center has developed a process concept for the solar thermal recycling of solid residues and waste materials in a commercial scale and applied this concept to the production of secondary aluminium. In this context a mathematical model for the simulation of the unsteady-state behaviour of a solar heated rotary kiln has been developed, which is used to figure out the specifics of the solar boundary conditions like intermittent insolation and at least one start-up period per day as well as for process design purposes. This model is also capable to simulate hybrid and conventionally fossil heated processes in rotary kilns.

The model was adapted and validated by recycling experiments using a rotary kiln in mini-plant scale heated by a solar furnace. Subsequent experimental results were in good agreement with the data predicted by the transient calculations. Taking this as a basis the model was applied to predict a possible operation concept for a stand-alone plant operated solar-only at El Paso, Texas. An important step for further design studies was the calculation of the overall efficiency and the number of cycles feasible at representative days in such a plant. In a representative parameter studies the influence of geometrical kiln parameters on the efficiency and cycle duration of the batch process was investigated.
\end{abstract}

(c) 2015 Elsevier Ltd. All rights reserved.

\section{Introduction}

The combustion of fossil fuels can be substituted by the application of concentrated solar radiation not only in power generation but also in chemical and metallurgical high temperature processes. The feasibility of solar power generation in a technical scale using central receiver systems for solar radiation has already been shown [1]. Similar plant concepts are generally suitable also for furnace based processes like the high temperature treatment of low

\footnotetext{
* Corresponding author. Tel.: +49 2203601 2673; fax: +49 220366900

E-mail address: martin.roeb@dlr.de (M. Roeb).
}

calorific materials and metals. In this case a furnace is used as radiation absorber and at the same time as reactor for the high temperature process. One important high temperature application is the recycling of aluminium, which delivers secondary aluminium, a strongly demanded product with a still growing market due to its use in the packing, the construction and especially the automotive industry.

One important reactor type, widely used in industrial aluminium recycling plants is the rotary kiln having high flexibility towards throughput and towards the kind and the metal content of the scrap. In conventionally heated kilns a natural gas-air or a natural gas-oxygen burner is mounted in the front door closing the reactor during the heating period. Even if the technology is in 


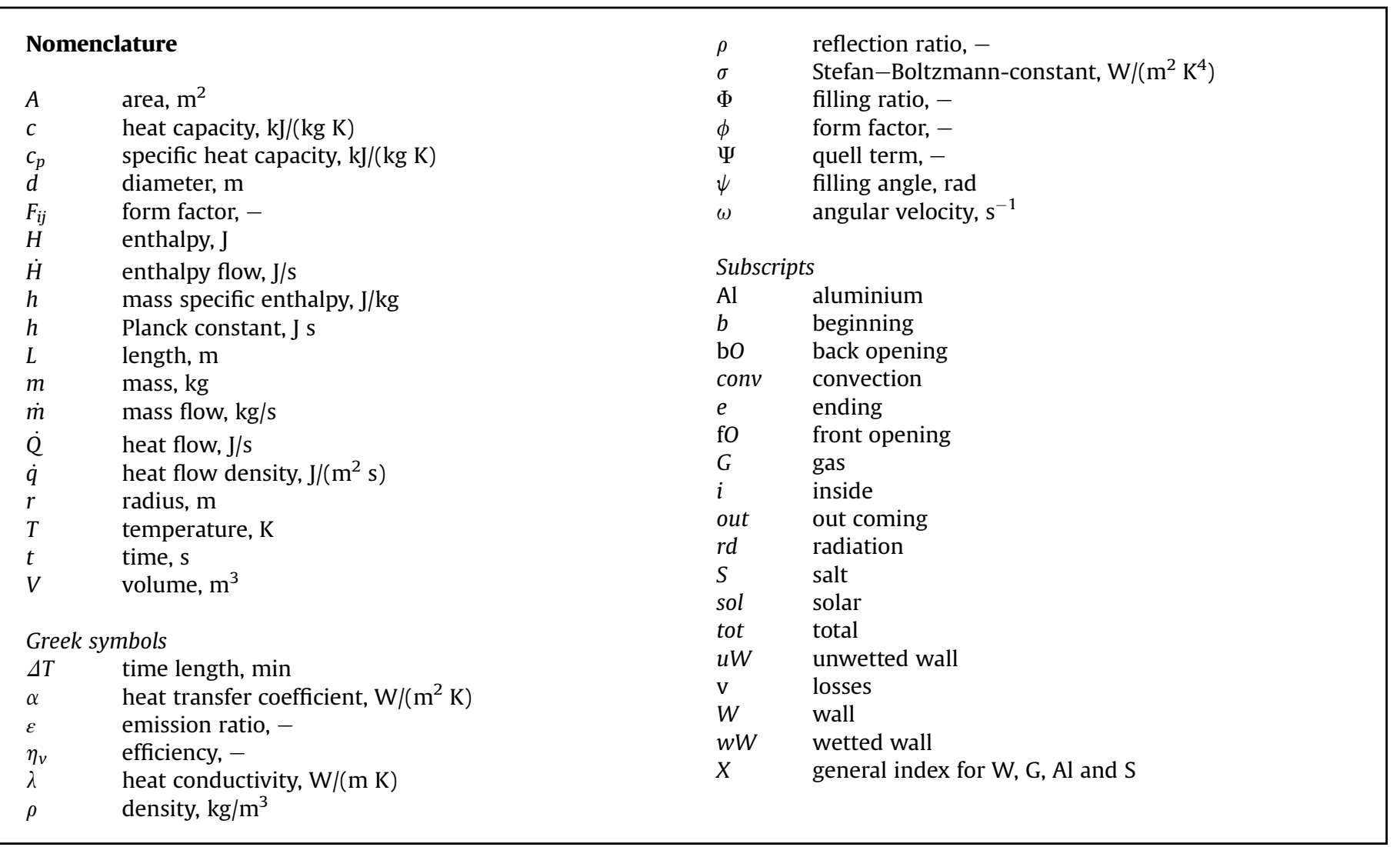

general established for many applications since several decades recent development address different new aspects to improve process performance related to heat transfer [2,3], energy consumption $[4,5]$, energy balance [6-8], material flow [9,10], mixing effects [11], flue gas treatment [12,13] etc. For solar operation of a rotary kiln an open aperture or a transparent window for introducing the radiation is needed [14-16].

Regarding solar application a rotary kiln has been proven to be a suitable unit for use as a direct absorbing receiver reactor to provide high temperature process heat [17]. In the $500 \mathrm{~kW}$ scale tests at the solar furnace in Odeillo, France, temperature levels up to $940{ }^{\circ} \mathrm{C}$ were achieved when heating sand as the heat carrier medium. Beyond that rotary kilns are rather universal tools in high temperature processes. Thus the results of the technology development in solar thermal recycling of aluminium may be diversified and transferred to processes like pyrolysis, detoxification of filter residues, metal containing dust and foundry sands, as well as the production of iron oxide based pigments and the production of cement or lime. Alonso and Romero give a comprehensive overview on the options in terms of coupling solar radiation to the different applications [18]. For example Meier et al. reported on the application of a rotary kiln for solar lime productions, its experimental proof by testing it in a solar furnace set-up [19-21] and by evaluating the economic potential [22]. Roeb et al. analysed the use of a rotary kiln for solar treatment of industrial residues and wastes [23], Navarro et al. did such analysis for wastes from mining [24]. Yilmazoglu et al. [25] analysed a solar assisted rotary coal dryer in terms of exergy, economy and environment. Bathen et al. compared different receiver and furnace technologies for solar aluminium melting and recycling [26]. Ahmad et al. even extended such concepts towards much higher temperatures allowing the melting of glass [27]. Neises, Tescari et al. investigated the use of a solar heated rotary kiln for metal oxide reduction experimentally [28] and by numerical simulation $[29,30]$.

To pave the path for a push of a solar technology for aluminium recycling into the market the following items have to be done: demonstration of technical feasibility in laboratory and pilot scale, concepts for industrial realisation of the technologies, assured predictions about feasibility in industrial scale, market and economic analysis as well as system integration.

An important instrument for the preparation and backing of the step from a mini-plant operation to the start-up of a pilot or even commercial sized plant is the use of simulation models. Compared to fossil or electrically heated kilns the solar heating of a kiln will bring about exceptional and uncommon operation conditions due to alternating insolation, which requires at least one start-up and one shut-down period per day. Beyond that the operation of the plant is batchwise. Therefore a mathematical model is necessary which allows to investigate the transient thermal behaviour of the process and to support the design of solar heated rotary kilns. The set-up, test, and application of such a model were task and objective of our investigations which are described in the following.

\section{Process and plant}

The classical remelting process for secondary aluminium production includes the melting of contaminated aluminium scrap in a conventionally fossil heated rotary kiln. The tasks of the kiln are melting and conditioning of the scrap and at the same time phase separation. For that purpose the kiln is being rotated and the scrap in the kiln is covered by a salt flux which typically is a mixture of $\mathrm{NaCl}$, $\mathrm{KCl}$ and $\mathrm{CaF}_{2}$. The flux has three main functions: a) prevention of oxidation of the molten aluminium by atmospheric oxygen which is sucked trough the kiln, b) support of the phase separation of 
aluminium and aluminium oxide and c) absorption of contaminants. The amount of the salt in process depends on the grade of decontamination of the scrap. For the heating natural gas-air or natural gas-oxygen burners mounted in the furnace door are applied.

The operation is batchwise. One furnace campaign includes different process steps: These are a) charging of scrap and flux, b) heating and melting, and c) discharging of aluminium smelting and slag. Only during step b the supply of heat is needed, during charging and discharging the furnace door is open and the burner is switched off. A model capable of describing the whole process has to take into account all these different steps.

Beside excess combustion air and false air the furnace atmosphere contains combustion gases like $\mathrm{CO}_{2}, \mathrm{CO}$ and partially oxidised organics, $\mathrm{HCl}$, and solid particles of $\mathrm{Al}_{2} \mathrm{O}_{3}$, spray of molten aluminium and flux. This atmosphere is sucked as flue-gas through the exhaust pipe, the components are separated and cleaned by filtration methods.

Rotary kilns are well suitable for being directly heated by concentrated solar radiation instead of fossil firing. In a solar application the kiln is used as a receiver-reactor: as a reactor for the remelting of aluminium scrap and at the same time as receiver absorbing the sunlight. First steps to develop the technology needed for that solar application were carried out at the DLR in Cologne. Therefore a mini-plant for solar aluminium recycling was constructed and operated to investigate the process behaviour and demonstrate the feasibility of the process [31]. The design of the plant has been continuously optimised. The heart of the mini-plant is a rotary kiln directly irradiated by concentrated solar radiation entering the reactor through a circular front opening (Fig. 1). The redirection and concentration of the solar radiation is done by a solar furnace in Cologne. The capacity of the rotary kiln is one to $2 \mathrm{~kg}$ of aluminium plus additional salt flux, which is charged through the front opening into a SiSiC-crucible. The focus of the solar furnace is located right in the aperture of the kiln, thus maximising the solar power input. The kiln is mounted on a tiltable frame allowing the discharge of molten metal and slag into moulds.

For the prevention of gaseous emissions through the front opening and for the combustion of organic components a slight stream of air is sucked through the reactor. The flue-gas which is generated during the process is piped through a heated exhaust gas line made of stainless steel and cleaned in a two-step washer. The temperatures at seven positions in the kiln and the exhaust-gas temperature are measured and telemetrically transferred to a data acquisition system. Gaseous components like $\mathrm{CO}_{2}, \mathrm{CO}$, and organic compounds in the flue-gas are measured online. Solid components in the flue gas can be determined by isokinetic probing and spectroscopic methods.

The operation of the solar process is analogue to the conventional process. The procedure runs as follows: First, the melting salt is charged and heated to $700-800{ }^{\circ} \mathrm{C}$. Afterwards the irradiation is interrupted and the scrap is charged into the molten salt. In the mini-plant rotary kiln manual stirring is needed in order to prevent that the shredded scrap remains on the surface of the salt smelting. Complete coverage of the scrap minimises oxidation losses. Thereafter the mixture is irradiated and heated again. Finally the molten aluminium and the salt slag are discharged into moulds. Salt and aluminium are separated after solidification. The usual fraction of salt in the conventional process is $30-50$ percent related to the scrap charge. A higher fraction of salt, $50-100 \%$, was chosen in the solar experiments in the mini-plant. This was due to the small amount of charged material related to the surface of the crucible and due to the large specific surface of the shredded scrap. A typical charge consisted of $0.5-1 \mathrm{~kg}$ UBC (shredded used beverage cans) and $0.5-1 \mathrm{~kg}$ melting salt.

The test campaigns show that solar thermal recycling of aluminium is feasible in a mini-plant scale and delivers a product of sufficient quality which is comparable to conventionally produced material.

A plant concept for the solar thermal recycling of aluminium in industrial scale has been developed. To supply the large heat demand of the melting process the solar thermal recycling plant has been designed as central receiver system as shown in Fig. 2, mainly consisting of the heliostat field, the receiver-reactor and the flue gas treatment. Characteristic of the central receiver system is that several individually aligned mirrors, so-called heliostats, reflect and concentrate the direct beam solar energy toward a common fixed focal area. The heliostats are realised as three-dimensional tracking mirrors with a field efficiency of typically about $70 \%$. The heliostat field has to be optimised for the intended annual yield of secondary aluminium at the special site of interest.

The receiver-reactor is realised as a rotary kiln with a total capacity of 8-20 t. For the design of the kiln two different approaches are conceivable. In the first case the concentrated solar beam passes an open receiver aperture, thus radiation preferentially heats the refractory wall of the drum and a melt film adhering to that wall of the kiln, whereas the bulk melt of the material to be treated is effectively mixed due to the rotation. An alternative way is to use a closed reactor system. In this case the solar radiation enters the kiln trough an aperture closed by a transparent quartz glass window. In the latter case a complete control on the furnace atmosphere is achieved.

To avoid severe shadowing and blocking of the redirected beam by adjacent heliostats, the focal zone has to be elevated above the plane of the heliostats. Therefore the rotary kiln is placed on top of a ramp having an optical height of about $20 \mathrm{~m}$ at the aperture with reference to the heliostat field. Due to reliability reasons the height has been restricted to the mentioned maximum value. A significantly reduced exhaust gas stream and less burning losses are the main advantages expected for the solar recycling concept.

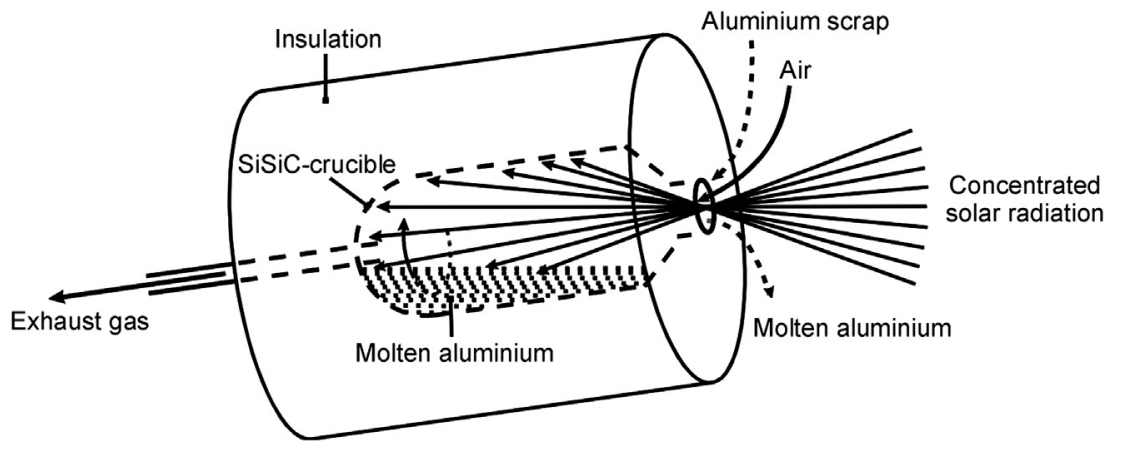

Fig. 1. Scheme of the mini-plant rotary kiln. 


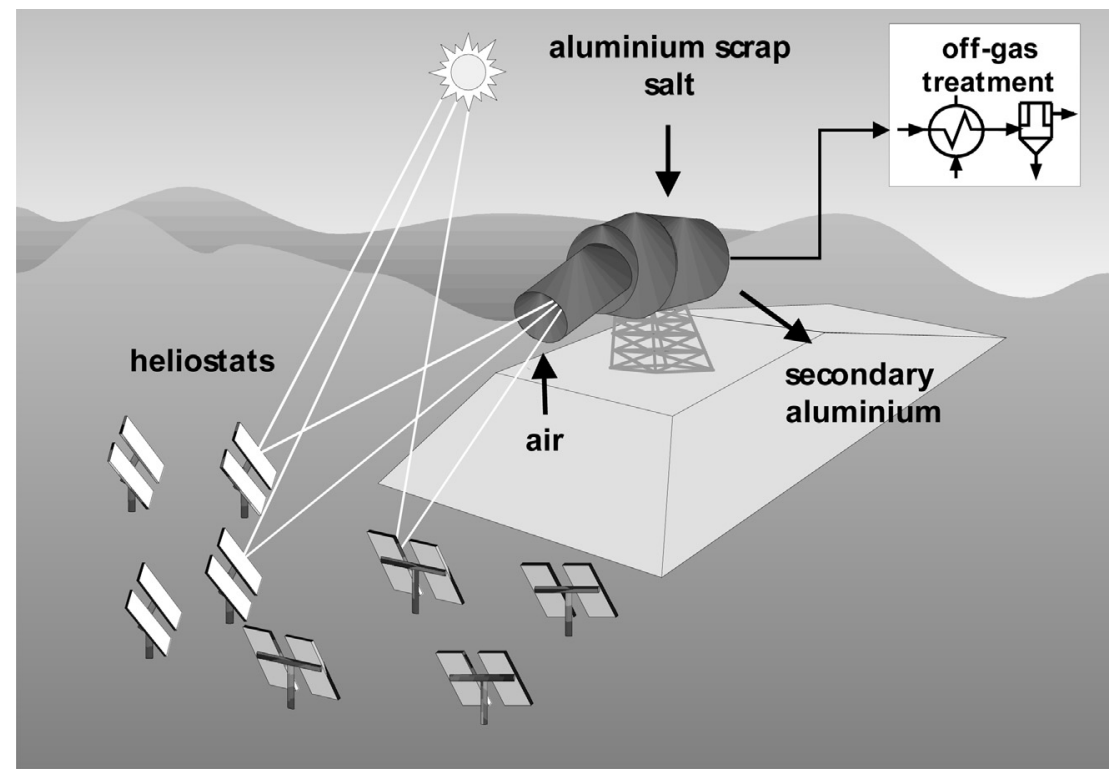

Fig. 2. Scheme of a solar thermal recycling plant.

\section{Model}

Due to the intermittence of solar radiation and due to the discontinuity of the recycling process mathematical modelling and computer-aided simulation is useful to improve the process knowledge, to analyse the effects of process changes, to examine the influence of alternating process conditions as well as to support the scale-up and for example the design of control systems. Therefore, a mathematical model for the simulation of the transient behaviour of a solar heated rotary kiln has been developed.

The kiln model consists of unsteady state one-dimensional heat transfer equations for each of the wall elements, dynamical energy balances for the aluminium, the salt and gas hold-up and additional equations for material properties and heat transfer [32]. As the simulation tool used in this case is capable to solve only first order differential equations in time, a finite difference scheme is applied to the heat transfer equations of the wall elements in order to resolve the space derivatives.

\subsection{Model geometry}

The components of the kiln model are presented in Fig. 3.

In this example the kiln is subdivided into three cells. The middle cell can be duplicated if necessary to get a higher resolution in this direction. Each cell contains models for the cylindrical wall, the bed, and the gas. The first and the last cell include a front and a back wall cover. Each cover has an opening: a front opening for charging and as entrance for the concentrated solar radiation and a smaller back opening enabling the suction of the exhaust gas. The cylindrical wall is subdivided into two segments allowing for different temperatures, a wall segment wetted by aluminium and salt and a wall segment in contact with the gas. Each wall is divided into three layers in radial direction: the refractory, the ceramic isolation, and the steel housing. The bed consists of two layers: molten salt as the upper layer in contact with gas and aluminium as the underlying layer.

\subsection{Energy and mass balance}

The considered mass flows of the gas, aluminium, and salt flux of the simulation model are shown in Fig. 4. Each cell has incoming and outgoing mass flow rates marked as $\dot{m}_{\text {in }, i}^{X}, \dot{m}_{\text {out }, i}^{X}(\mathrm{X} \in(\mathrm{G}, \mathrm{S}, \mathrm{Al}))$ representing the charging and discharging flow rates. They must be provided by an input file as function of the time. Beside these external flow rates, there are internal mixing flows for salt and aluminium, $\dot{m}_{i \rightarrow i+1}^{X}, \dot{m}_{i+1 \rightarrow i}^{X}$, which are model parameters. Due to mass conservation these flow rates are paired and they are considered to have the same values.

For the gas no backmixing flow is considered due to the constant sucking through the kiln. The index $\mathrm{i}=1, \ldots 3$ refers to the cell number.

The following general Equation (1) for each of the three cells describes the mass balance for aluminium, salt and gas. It needs to be taken into consideration that the mass transfer in the middle section occurs from both neighbouring sides due to mixing, whereas the mixing the two outer sections receive mass transfer from only one side.

$\frac{\partial m_{X}}{\partial t}=\dot{m}_{i n, i}^{X}-\dot{m}_{o u t, i}^{X}+\dot{m}_{i-1 \rightarrow i}^{X}-\dot{m}_{i \rightarrow i-1}^{X}+\dot{m}_{i+1 \rightarrow i}^{X}-\dot{m}_{i \rightarrow i+1}^{X}$

where

$\begin{array}{ll}\dot{m}_{i-1 \rightarrow i}^{X}=\dot{m}_{i \rightarrow i-1}^{X}=0 & \text { for } \quad i=1 \\ m_{i+1 \rightarrow i}^{X}-\dot{m}_{i \rightarrow i+1}^{X}=0 & \text { for } \quad i=3 .\end{array}$

Neglecting chemical reactions and using variable mass content the energy balance may be written as:

$$
\begin{aligned}
\frac{\partial H_{X, i}}{\partial t}= & \dot{m}_{i n, i}^{X} \cdot h_{S, i-1}-\dot{m}_{o u t, i}^{X} \cdot h_{X, i}-\dot{m}_{i \rightarrow i-1}^{X} \cdot h_{X, i}+\dot{m}_{i-1 \rightarrow i}^{X} \cdot h_{X, i-1} \\
& +\dot{m}_{i+1 \rightarrow i}^{X} \cdot h_{X, i+1}-\dot{m}_{i \rightarrow i+1}^{S} \cdot h_{X, i}+\dot{Q}_{\text {tot }}^{X}
\end{aligned}
$$

The energy balance of the gas, the aluminium, and the salt for each cell is considered transient as can be seen from Equation (2). The sum of the heat fluxes consists of convective and radiative losses and the solar source term $\dot{Q}_{\text {sol }}^{X}$.

$\dot{Q}_{\text {tot }}^{X}=\dot{Q}_{\text {conv }}^{X}+\dot{Q}_{r d}^{X}+\dot{Q}_{\text {sol }}^{X}$

The gas is assumed to not absorb any solar radiation and to transport heat only by convection. Only the surface of the flux, the 

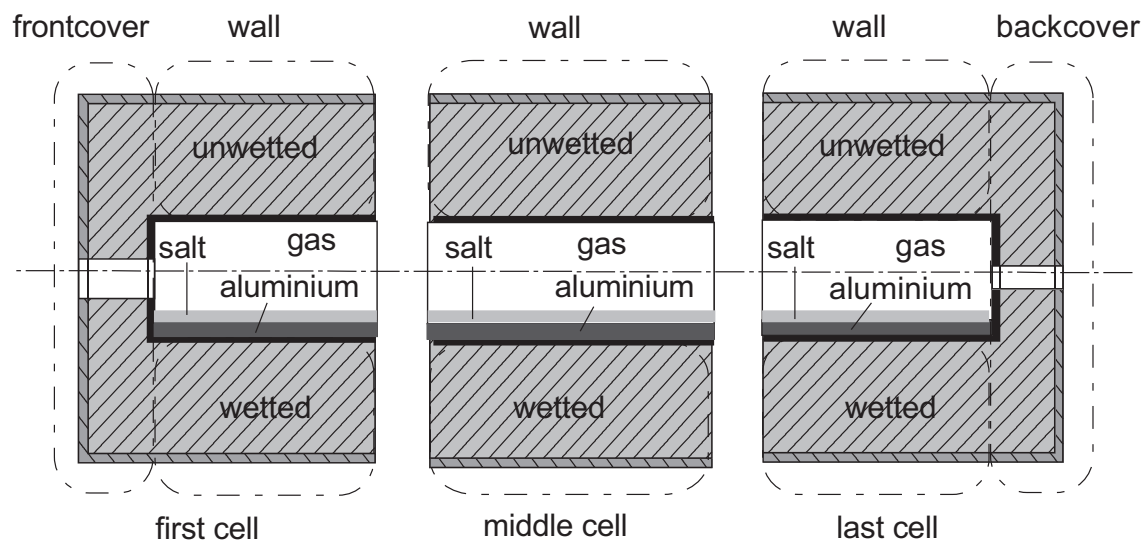

Fig. 3. Components of the kiln model for three cells.
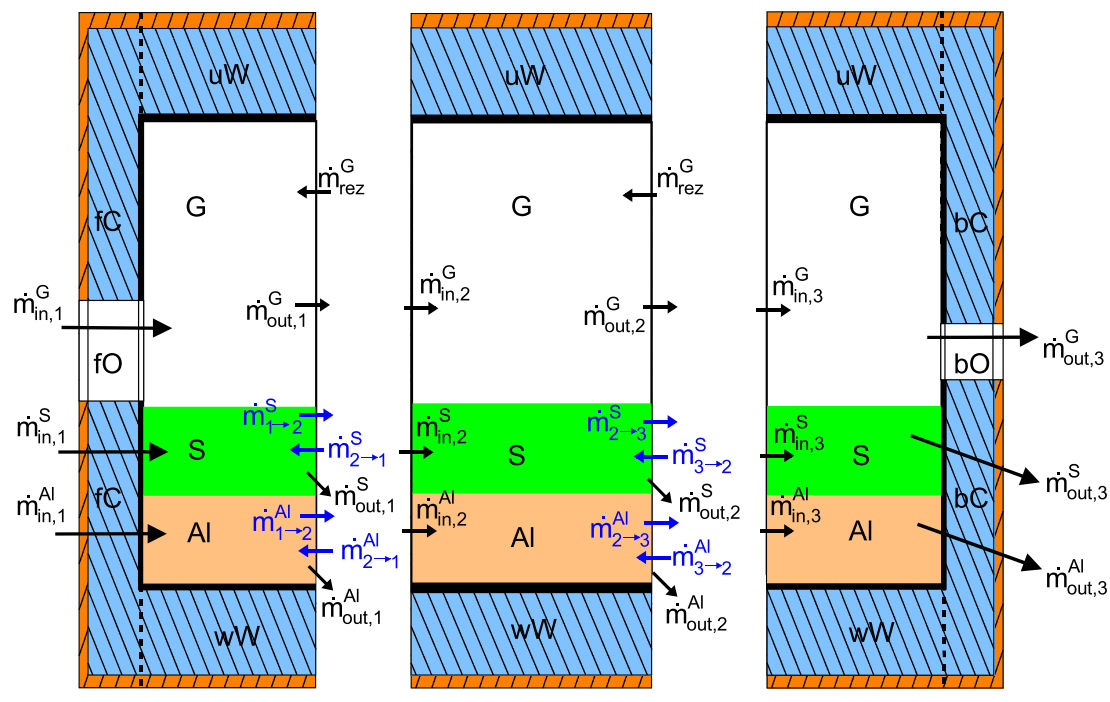

Fig. 4. Considered mass flow in the rotary kiln model.

back cover, and the unwetted wall of the interior of the kiln are directly irradiated by the concentrated sunlight. The magnitude of the solar heat flux considered in Equation (3) is assumed to be dependent of the solar flux entering the kiln and of the geometrical ratio of the surface been direct irradiated by concentrated sunlight to the sum of all direct irradiated surfaces. The aluminium has only a convective heat flux because it is covered by the salt. The temperature of the aluminium, gas and salt in one single cell is independent of the location and the pressure is constant. Heat absorbed by the salt is transported by convection to both front and back cover of the kiln, to the aluminium, and to the gas.

The radiative heat flux of each media participating in the radiative interaction can be calculated by the following equation

$\dot{Q}_{r d}^{X}=-\frac{A_{X} \cdot \varepsilon_{X}}{\left(1-\varepsilon_{X}\right)} \cdot\left(\sigma \cdot T_{X}^{4}-\dot{q}_{a}^{X}\right)$

For the heat flux due to convection applies the following common used equation

$\dot{Q}_{\text {conv }}^{i, j}=\alpha_{i, j} \cdot A_{i, j} \cdot\left(T_{j}-T_{i}\right)$

The heat transfer coefficients are variable. Generally for each case the following function approach is been used $\alpha_{i, j}=\alpha_{i, j}(\operatorname{Re}, \operatorname{Pr}, N u$, Geometry, $\lambda, \omega)$

In the case of the transfer from the gas to the salt, the function of Gorog [33] has been used:

$\alpha_{i, j}=0,4 \cdot\left(\frac{3600 \cdot \dot{m}_{G}}{A_{G}}\right)^{0,62}$

For the heat transfer from the gas to the walls the following approach of Patisson [34] is used:

$\alpha_{G, u W}=0,036 \cdot \frac{\lambda_{G}}{d_{i}} \cdot \operatorname{Re}^{0,8} \cdot \operatorname{Pr}^{0,33} \cdot\left(\frac{d_{i}}{L}\right)^{0,055}$

Non-stationary one dimensional heat conduction through each wall segment is considered. Heat conduction through the walls and the front and back cover is assumed to be one-dimensional and perpendicular to the wall. The wall of the kiln consists of three homogenous layers, each with four wall temperatures.

The temperature of the wall is variable in time and in the radial direction. Furthermore the cylindrical kiln wall is divided into two segments in order to distinguish between the wetted and den unwetted part. The temperature field is calculated by Equation (9), 
which results from the first law of thermodynamics in combination with Fourier's law of heat conduction [35].

$\rho \cdot c \cdot \frac{\partial T}{\partial t}=\nabla(\lambda \nabla T)+\Psi$

Heat sources inside the wall do not exist. Considering the dependence in radial direction the equation modifies to:

$\rho \cdot c \cdot \frac{\partial T}{\partial t}=\frac{1}{r} \frac{\partial}{\partial r}\left(r \cdot \lambda \cdot \frac{\partial T}{\partial r}\right)=\frac{\partial}{\partial r}\left(\lambda \cdot \frac{\partial T}{\partial r}\right)+\frac{\lambda}{r} \frac{\partial T}{\partial r}$

The solution of this differential equation is raised by an explicit difference method. The rotation of the kiln is included by considering additional enthalpy fluxes for each volume element (Fig. 5) [36]:

$\frac{\partial H_{W, i, j}}{\partial t}=\dot{Q}_{i, \text { in }}^{W}-\dot{Q}_{i, \text { out }}^{W}+\dot{H}_{j, \text { in }}^{W}-\dot{H}_{j, \text { out }}^{W}$

The terms $\dot{Q}_{i, z u}^{W}$ and $\dot{Q}_{i, a b}^{W}$ consider the heat conduction in radial direction, whereas the enthalpy heat flows $\dot{H}_{j, z u}^{W}, \dot{H}_{j, a b}^{W}$ imply the rotation of the kiln.

After some simplifications the following equation is used for the calculation of the unwetted wall temperature at the first wall layer of the rotary kiln

$$
\begin{aligned}
\frac{\partial T_{i}^{u W}}{\partial t}= & \frac{\lambda}{\rho \cdot c \cdot \Delta r}\left(\frac{T_{i-1}^{u W}-2 T_{i}^{u W}+T_{i+1}^{u W}}{\Delta r}+\frac{1}{2 r_{i}}\left(T_{i+1}^{u W}-T_{i-1}^{u W}\right)\right) \\
& +\frac{\omega}{2 \pi-\psi}\left(T_{i}^{w W}-T_{i}^{u W}\right)
\end{aligned}
$$

The last term in this equation considers the heat flow due to the rotation of the kiln. For their description only the information about the momentary wall temperatures, the rotational speed and the filling angle are needed. The energy balances of the other wall segments in each of the three wall layers is referred to the work of Schöler [37].

\subsection{Radiative heat transfer}

Concentrating solar radiation is partially absorbed and reflected at the surface segments within the rotary kiln. The high wall temperatures during most of the kiln operating time imply a high significance of radiative heat transfer. Therefore, a model for the radiative heat exchange occurring among the exposed wall and bed surfaces is essential for any kiln model.

Possible solution methods for the calculation of radiation phenomena are flux methods like the moment method [38] and the

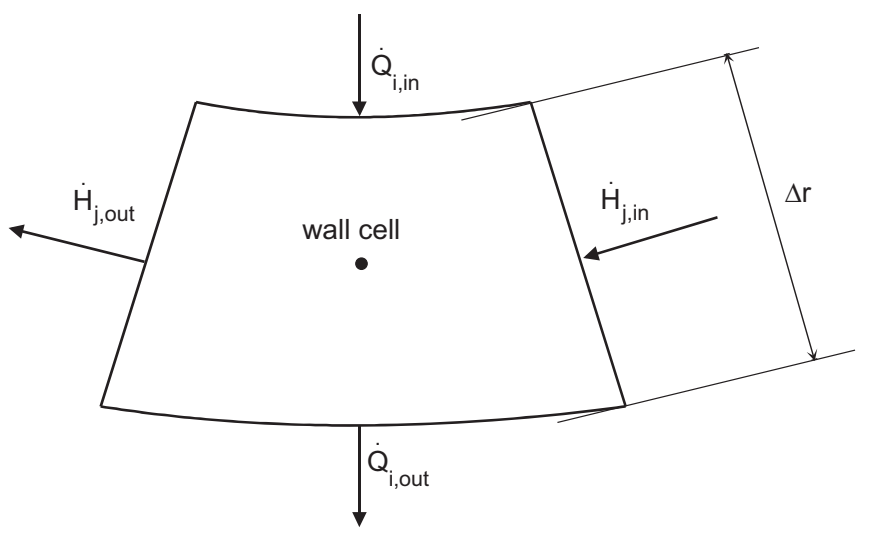

Fig. 5. Energy balance for a wall cell. zone method. Radiative heat transfer inside the rotary kiln is calculated according to the latter method [39]. This method is very accurate and widely used.

While using this method following assumptions have been made:

- the laws of Lambert and Kirchhoff apply for the system

- the front and the back opening behave like black bodies

- the gas inside the kiln does not participate to the radiation because the concentrations of $\mathrm{H}_{2} \mathrm{O}$ and $\mathrm{CO}_{2}$ are very low

- the wall of the kiln and salt flux are considered as diffuse-grey surfaces

- the scattering of radiation at the gas molecules has been neglected

Characteristic of the method is that the inner surface and the enclosed volume of the kiln is divided into a number of zones, each assumed to have a uniform distribution of temperature and uniform radiative properties. For each zone an energy balance equation is drawn. Form factors are used for the description of the radiative interchange between the surfaces. The zone method reduces the radiative heat transfer problem to the solution of a set of non-linear algebraic equations. A standard source explaining this method in detail is [40].

For each zone an energy balance equation is considered. The exiting heat flux is composed of an emissive and a reflective term. After transformations a relation is derived for the net heat flux at any surface of the rotary kiln. A detailed description of this procedure can be found in Ref. [41].

\subsection{Numerical tool}

The special programming language SMILE was chosen for the simulation of rotary kilns. SMILE is an object-oriented, equationbased simulation language. SMILE was developed for the dynamical simulation of complex energy conversion systems at the TU Berlin and GMD first [42]. SMILE is an extension of Objective-C and its syntax is very similar to this programming language. The objectoriented modelling approach eases re-usage of the developed code and avoids multiple implementations of almost identical models. A further advantage of object-oriented modelling is the detailed description of the reactor with increasing complexity. SMILE contains also numerical solution methods, which are capable to solve the algebro-differential-equation systems. The simulation process can be divided in three stages [43]: Initialization phase, simulation phase and finalization phase The SMILE compiler checks the model consistent and compiles all relevant files to executables. In the first phase of the initialization the whole equation systems is formed and optimized. In this stage for example algebraic equations are marked in order to simplify the solving process. In the simulation phase the numerical solver is initialized. Special solvers exist for the solving of the differential-algebraic equations of the model. This is important since at the beginning the first time increment is calculated. The result then is controlled from the runtime system. As soon as the first increment is checked the numerical solver solves the equation systems for the next time increment. In the finalization phase the form of the presentation of the results is set.

\subsection{Verification by experiments}

The model was validated with experiments of the mini-plant mentioned above and with data from a gas-heated rotary kiln. Data from melting experiments performed in the mini-plant rotary kiln in the solar furnace in Cologne were compared with simulation 
results. In a representative experiment applied for the validation the rotary kiln was heated using a heating ramp which had been optimised in preliminary experiments (Fig. 6). Before the irradiation started $0.5 \mathrm{~kg}$ salt and $1 \mathrm{~kg}$ aluminium were charged subsequently into the kiln. After $1.5 \mathrm{~h}$ the molten aluminium was discharged while the salt slag remained inside. After that another charge of equal composition as the first one was filled in and melted.

Fig. 7 shows a comparison between the wall temperature measured and simulated. During the experiment the wall temperature of the crucible was measured at different locations at the outer surface of the crucible. Two representative experimental temperature curves (T4 and T7) are included in Fig. 7.

The agreement is satisfactory. Similar simulations of further experiments in the solar furnace were carried out. They were used for the verification of the model. The agreement between predictions and measurements confirms that significant information about temperature profiles of the refractory and insulation can be derived from model simulations.

A small deviation between the measured and calculated data appears for high temperatures due to the assumptions and the approximations applied for the characterisation of the data on chemical media for the wall. On the contrary the thermal behaviour, for example sudden drops of the temperature due to switchoff of solar input, is satisfactorily portrayed.

The analysis seems to confirm that the thermal capacities for both crucible and the gas together with the corresponding transport phenomena are well represented mathematically and that the model can be considered reliable and useful for further simulation studies.

\section{Results}

\subsection{Simulation of the process in commercial scale}

The simulation model enables to consider loading and discharging processes and can be used for process design purposes and scale-up considerations. As an example for its application with regard to scale-up purposes the simulation results of three subsequent operating days in El-Paso, Texas, are shown for a large solarheated kiln in the next figures. With a length of $5 \mathrm{~m}$ and a capacity of $8000 \mathrm{~kg}$ of aluminium scrap the kiln is medium sized compared to conventional industrial applications of this kind.

In Fig. 8 the solar radiation flux entering the front opening of the kiln is depicted compared to the total available flux. The air mass flow which is necessary to avoid emission of exhaust-gas through the front opening amounts to $700 \mathrm{~kg} / \mathrm{h}$.

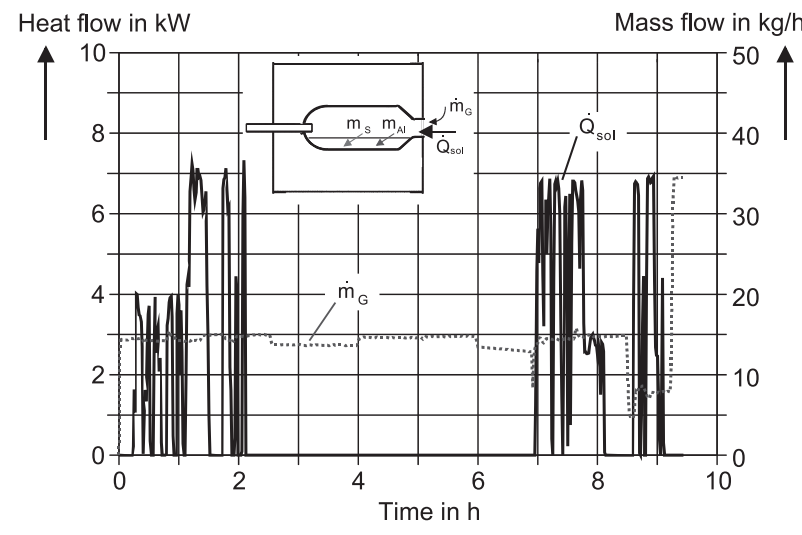

Fig. 6. Solar power input and gas mass flow in a typical experiment.

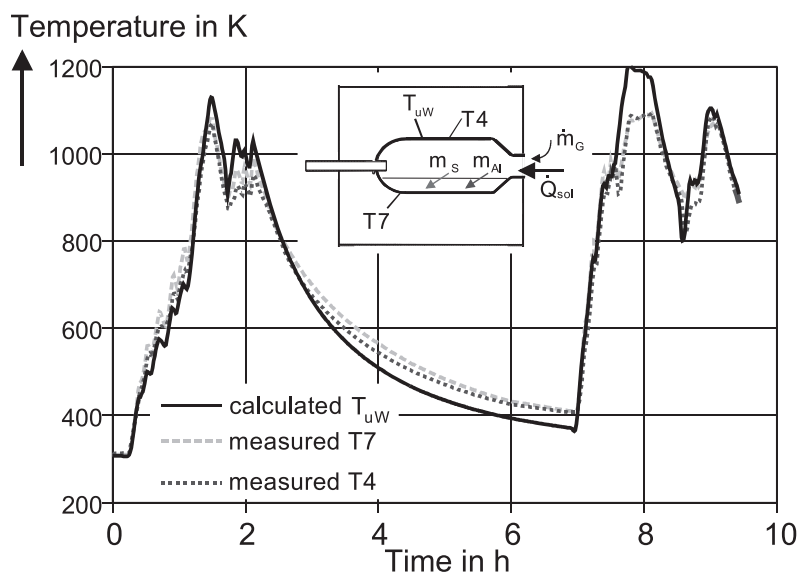

Fig. 7. Comparison of measured and calculated wall temperatures.

The warm-up has to be done with a moderate heating rate to avoid sudden expansion effects which may compromise the robustness and the reliability of refractory and insulation materials. After the start-up at the first day by heating the empty furnace the melting of five charges of raw material is possible during the second and third day. Before the charging of aluminium, salt is filled in the kiln and melted. From the second day on it is possible to melt four complete charges of aluminium of $8000 \mathrm{~kg}$ each day and a reduced charge of $6000 \mathrm{~kg}$. During the charging of aluminium the solar radiation cannot be used and the heliostats have to be defocused. The whole cycle of defocusing, tipping and filling with new aluminium mass was estimated to last approximately $50 \mathrm{~min}$.

In the first night storage heat remains in the refractory of the kiln, so that the first charging of aluminium at the second day takes place at a higher temperature level compared to the first day. In the night of the second day the wall is cooled down only to temperatures of about $600{ }^{\circ} \mathrm{C}$ due to the effective storage of heat and due to good isolation by closing the kiln door.

Fig. 9 shows the temperature curve of the flux and aluminium for the three days simulation. Due to numerical reasons, the model requires that small amounts of aluminium and salt always remain inside the kiln. The temperature of those small amounts of $1 \mathrm{~kg}$ each is determined by the wall temperature. The melting temperature of aluminium is $660{ }^{\circ} \mathrm{C}$ indicated by the hold point in the temperature curve of aluminium when having reached that temperature.

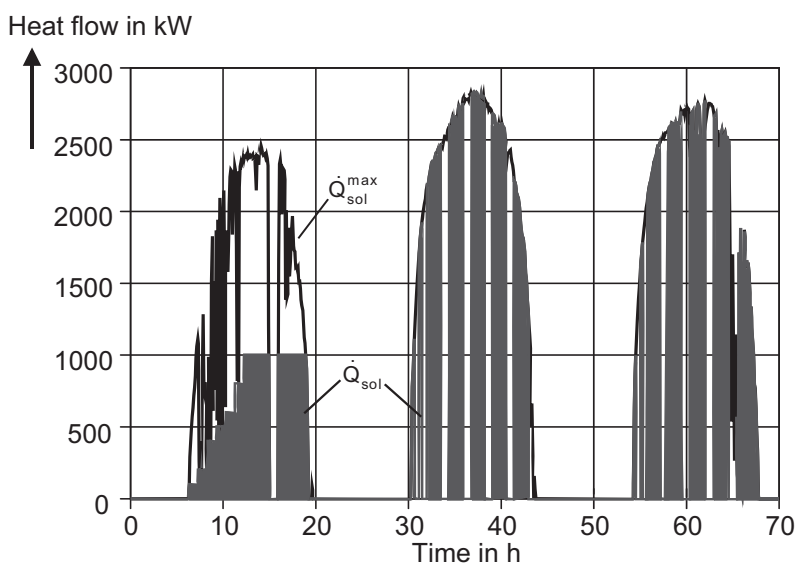

Fig. 8. Curves of the maximum available solar power and of the actually used reactor power for a three day simulation of a rotary kiln in commercial scale at El Paso, Texas. 
Temperature in $\mathrm{K}$

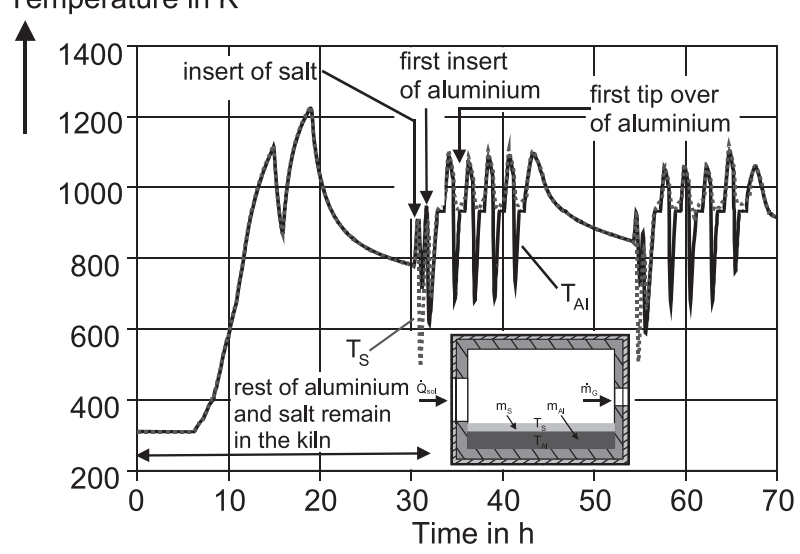

Fig. 9. Salt and aluminium temperature for the three day simulation of the large kiln.

Considering the second day and the fourth smelting cycle lasting $2 \mathrm{~h}$ we get the Sankey diagram of Fig. 10. During this cycle more than three fourth of the solar power entering the kiln are transferred to the aluminium and are used for heating and melting. The heat losses amount $10 \%$ of the power entering the reactor.

Considering the time interval, in which the reactor is in operation, the efficiency $\eta_{v}$ can be determined by integrating the relevant heat flows. The efficiency can be calculated for a solar-heated rotary kiln through the following equation according to [2].

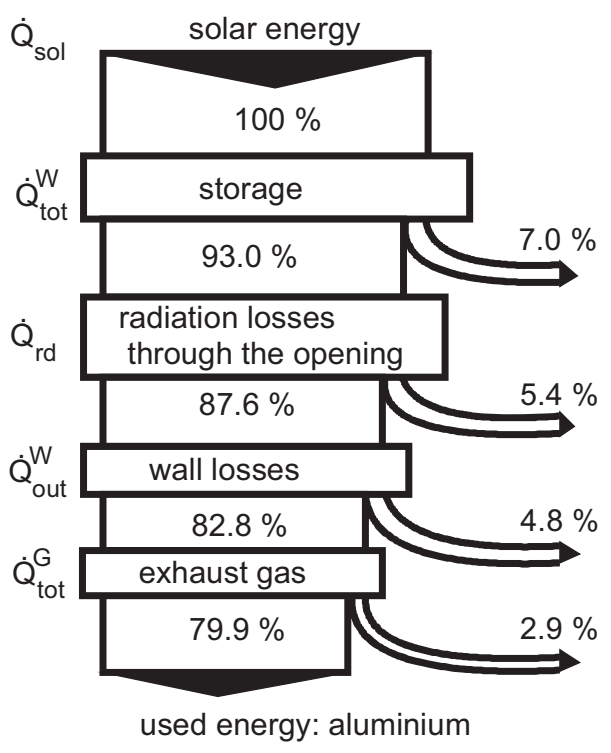

Fig. 10. Sankey diagram for a two hours smelting cycle at the second operation day of the large kiln.

The reactor is preheated to $800{ }^{\circ} \mathrm{C}$ which is characteristic for the operation of such a plant. The mass of the feed material and the gas flow for the reference case are as indicated in Table 2.

$\eta_{v}=\frac{\int_{t_{b}}^{t_{e}} \dot{Q}_{t o t}^{A l} d t}{\int_{t_{b}}^{t_{e}} \dot{Q}_{s o l} d t}=\frac{\int_{t_{b}}^{t_{e}} \dot{Q}_{s o l} d t-\int_{t_{b}}^{t_{e}}\left(\dot{Q}_{r d}^{f O}+\dot{Q}_{r d}^{b O}\right) d t-\int_{t_{b}}^{t_{e}} \dot{Q}_{o u t}^{W} d t-\int_{t_{b}}^{t_{e}} \dot{Q}_{t o t}^{G} d t-\int_{t_{b}}^{t_{e}} \dot{Q}_{\text {tot }}^{S} d t-\int_{t_{b}}^{t_{e}} \dot{Q}_{\text {tot }}^{W} d t}{\int_{t_{b}}^{t_{e}} \dot{Q}_{s o l} d t}$

The losses at the openings are the sum of the terms $\dot{Q}_{r d}^{\text {fo }}$ and $\dot{Q}_{r d}^{b O}$. The wall losses $\dot{Q}_{\text {out }}^{W}$ consist of the contributions of wetted and unwetted cylindrical wall segments as well as of both covers. The net heat flow $\dot{Q}_{\text {tot }}^{W}$ to the walls can be also be separated in the same way.

By consideration of the total duration of three simulation days with the first preheating day the efficiency amounts to 0.52 . Excluding the day for start-up the efficiency for a day with five smelting cycles amounts to 0.72 like i.e. for the third day of the simulation.

\subsection{Parameter study}

Operation and construction parameters affect the efficiency of rotary kiln reactors. Their influence is important under the aspect of energy efficiency, construction, and operation of the plant as well as under product quality control. For the investigation of the effect of these parameters a typical rotary kiln reactor was first chosen as a reference case and then the parameters were varied [34]. The variation of more than one parameter at the same time is avoided, because this complicates the interpretation of the individual effects. The effect of changing more than one parameter, however, can be found by summing up the effects of different parameters if the furnace condition does not differ too strong from the reference case. The main geometrical characteristics of the cylindrical shaped reference kiln are as follows (Table 1 ):
The efficiency and the duration of one re-melting cycle are two of the most important terms for the economical efficiency of a plant. Therefore these terms were chosen for the parameter study. One re-melting cycle includes the charging of aluminium and salt flux, the melting, and the discharging. The emptying of the rotary kiln takes place when the temperature of the aluminium has reached $750{ }^{\circ} \mathrm{C}$. This value is a typical temperature for that process in conventional kilns.

Effects of multiple aspects of furnace design and numerous operating parameters and model parameters have been investigated regarding their influence on efficiency and cycle duration. In this paper only the results of the effect of two selected geometrical parameters will be shown as representative examples. These two parameters are the furnace size and the aspect ratio $\left(\mathrm{L} / \mathrm{d}_{\mathrm{i}}\right)$. In order to investigate this influence the kiln length is varied between 3.6 and $6 \mathrm{~m}$, the inner diameter at the same time between 2.4 and $4 \mathrm{~m}$ in such way that the ratio $\mathrm{L} / \mathrm{d}_{\mathrm{i}}$ remains constant at 1.5 . The amount of charging material is the same in all these cases.

Table 1

Geometrical characteristics of reference kiln.

\begin{tabular}{llll}
\hline $\begin{array}{l}\text { Length of } \\
\text { kiln interior }\end{array}$ & $\begin{array}{l}\text { Diameter of } \\
\text { kiln interior }\end{array}$ & $\begin{array}{l}\text { Diameter of front } \\
\text { side opening }\end{array}$ & $\begin{array}{l}\text { Diameter of rear } \\
\text { side opening }\end{array}$ \\
\hline $4.8 \mathrm{~m}$ & $3.2 \mathrm{~m}$ & $1.36 \mathrm{~m}$ & $0.5 \mathrm{~m}$ \\
\hline
\end{tabular}


Table 2

Process parameters applied in the reference case.

\begin{tabular}{lll}
\hline Mass of charged aluminium & Mass of salt & Mass flow of air \\
\hline $8000 \mathrm{~kg}$ & $4000 \mathrm{~kg}$ & $700 \mathrm{~kg} / \mathrm{h}$ \\
\hline
\end{tabular}

The effect of the aspect ratio is investigated by variation of the kiln diameter while length remains constant. Therefore the reactor length is fixed to $4.8 \mathrm{~m}$ and the diameter is varied between 2.4 and $4 \mathrm{~m}$.

The results of the calculations show following tendencies:

With increasing size of the kiln and with decreasing aspect ratio the efficiency decreases and the necessary treatment time increases, see Fig. 11. The main reason for that is the decreasing efficiency of heat transfer to the aluminium with increasing size/ volume of the kiln. This effect influences the efficiency and the cycle length by far stronger than the increase of losses due to an increased surface. Regarding the losses the variation of diameter has a stronger impact than the variation of length due to the $\mathrm{d}^{2}$ dependency of the kiln surface.

These results fulfil the expectations, because an increase of the size with the aspect ratio remaining constant implies:

- The radiation terms from the walls increase, so that more heat through radiation rather than through convection reaches the salt. Due the small heat conductivity of the salt the heat transfer to the aluminium gets less effective.

- Heat losses to the environment through the openings and the walls by radiation and natural convection increase, because the outer surface of the kiln and the opening diameter become larger.

- The ratio of mass of aluminium to kiln surface get smaller and therefore less favourable.

- The increase of size causes a stronger increase in losses and more distinctly prolongs the treatment time compared to the variation of aspect ratio, which means here only the variation of kiln diameter. This is due to the simultaneous enlargement of diameter and length causing a stronger increase of the overall kiln size.

These facts - higher losses and less effective heat transfer to the aluminium - provoke a decrease of the efficiency and an increase of the cycle duration with increasing diameter and increasing length. The cross tagged curve in Fig. 11 shows that the highest aspect ratio corresponds to the highest efficiency of about 0.9 . This is also due to

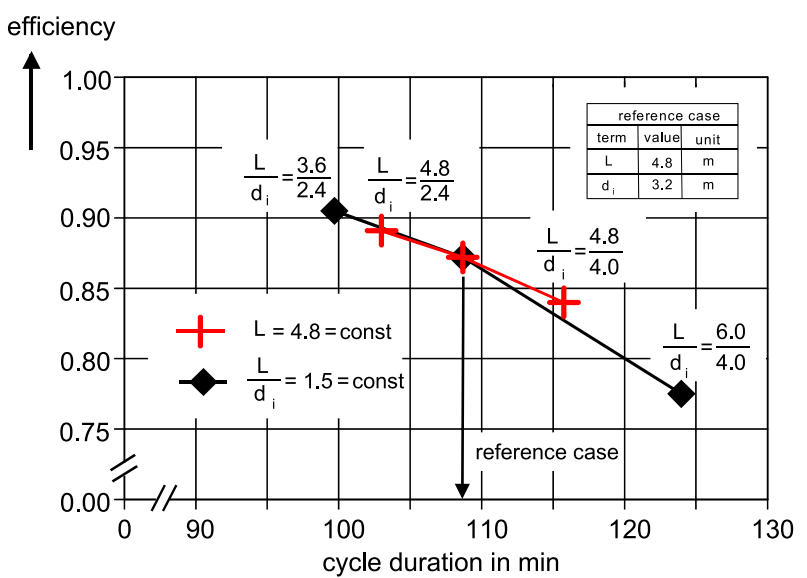

Fig. 11. Effect of the reactor size and the aspect ratio on the melting cycle duration and the efficiency. better heat transport to the aluminium compared to the other two investigated cases with lower aspect ratios. This confirms the result of a similar study of Song [44] for a gas-fired plant.

\section{Conclusions}

A mathematical model for the calculation of transient process behaviour of aluminium recycling in solar heated rotary kilns has been developed. The model enables the consideration of instationary process conditions regarding the batchwise operation and regarding intermittent supply of solar energy due to the day-night cycle and due to alternating cloudiness.

The model was adapted and validated by recycling experiments using a rotary kiln in mini-plant scale heated by a solar furnace. It was applied for scale-up purposes and for predictions about the process behaviour of commercial scale aluminium recycling plants. The development of a concept for an industrial recycling plant was supported by using this tool. The calculated data were compared with experimental data provided by recycling experiments carried out in a solar heated mini-plant. The calculated marches of temperature are always in good accordance with the experimental findings. Only small deviations between the measured and calculated data appear at high temperatures due to model assumptions and the used approximations.

The model was applied to predict a possible operation concept for a stand-alone plant operated in solar-only-mode at El Paso, Texas. The considered rotary kiln has a capacity of about $8 \mathrm{t}$ of scrap. In the considered period the calculations predict the feasibility of re-melting four complete charges and one reduced charge during one day after one start-up day. Neglecting the day for the start-up the predicted efficiency of the solar heated amounts to 0.72 at a day with good insolation.

In a representative parameter study the influence of kiln size and its aspect ratio on the efficiency and cycle duration was investigated. Increasing kiln size and aspect ratio cause decreasing efficiency of heat transfer and higher losses. This diminishes the efficiency and increases the time for the treatment of one batch.

The next step will be the implementation of mass transfer between solid/molten and gas phase which will allow for predictions about important process parameters like oxidation losses and offgas composition. The model is being modified to enable also the calculation of conventionally gas fired and hybrid heated rotary kilns being essential if a $24 \mathrm{~h}$-operation of the plant is needed or desired.

\section{Acknowledgements}

The authors gratefully acknowledge the financial support of the Solar Energy Association and the Ministry of Schools, Education and Research of the Federal State of North Rhine-Westphalia, Germany (Project nos. 25513696 and 263502 99) and of the German Aerospace Center.

\section{References}

[1] P. Kesselring, C.S. Selvage (Eds.), The IEA/SSPS Solar Thermal Power Plants, Volume 1: Central Receiver System (CRS), Springer-Verlag, Berlin, Germany, 1986.

[2] L. Le Guenn, F. Huchet, J. Dumoulin, A wall heat transfer correlation for the baffled-rotary kilns with secondary air flow and recycled materials inlet, Exp. Therm. Fluid Sci. 54 (2014) 110-116.

[3] F. Herz, I. Mitov, E. Specht, R. Stanev, Influence of operational parameters and material properties on the contact heat transfer in rotary kilns, Int. J. Heat Mass Transfer 55 (2012) 7941-7948.

[4] A. Atmaca, R. Yumrutaş, Analysis of the parameters affecting energy consumption of a rotary kiln in cement industry, Appl. Therm. Eng. 66 (2014) 435-444. 
[5] V. Karamarković, M. Marašević, R. Karamarković, M. Karamarković, Recuperator for waste heat recovery from rotary kilns, Appl. Therm. Eng. 54 (2013) $470-480$.

[6] X. Fan, J. Li, X. Chen, Y. Wang, M. Gan, Temperature field simulation model for rotary kiln of iron ore oxidized pellet, J. Iron Steel Res. Int. 20 (2013) 16-19.

[7] A. Mezquita, J. Boix, E. Monfort, G. Mallol, Energy saving in ceramic tile kilns: cooling gas heat recovery, Appl. Therm. Eng. 65 (2014) 102-110.

[8] M. Gürtürk, H.F. Oztop, Energy and exergy analysis of a rotary kiln used for plaster production, Appl. Therm. Eng. 67 (2014) 554-565.

[9] Hongchao Yin, Ming Zhang, Hong Liu, Numerical simulation of threedimensional unsteady granular flows in rotary kiln, Powder Technol. 253 (February 2014) 138-145.

[10] A.S. Bongo Njeng, S. Vitu, M. Clausse, J.-L. Dirion, M. Debacq, Effect of lifter shape and operating parameters on the flow of materials in a pilot rotary kiln: part I. Experimental RTD and axial dispersion study, Powder Technol 269 (January 2015) 554-565.

[11] A.R. Nielsen, R.W. Aniol, M. Boberg Larsen, P. Glarborg, K. Dam-Johansen, Mixing large and small particles in a pilot scale rotary kiln, Powder Technol. 210 (2011) 273-280.

[12] D.A. Granados, F. Chejne, J.M. Mejía, C.A. Gómez, A. Berrío, W.J. Jurado, Effect of flue gas recirculation during oxy-fuel combustion in a rotary cement kiln, Energy 64 (2014) 615-625.

[13] K.-L. Lam, A.O. Oyedun, C.-W. Hui, CFD study on the application of rotary kiln in pyrolysis, in: E.N. Pistikopoulos, M.C. Georgiadis, A.C. Kokossis (Eds.), Computer Aided Chemical Engineering, vol. 29, Elsevier, 2011, pp. 71-75.

[14] A.M. Mecit, F.J. Miller, A. Whitmore, Optical analysis and thermal modeling of a window for a small particle solar receiver, Energy Procedia 49 (2014) 457-467.

[15] G.-L. Dai, X.-L. Xia, G.-F. Hou, Transmission performances of solar windows exposed to concentrated sunlight, Sol. Energy 103 (2014) 125-133.

[16] C.K. Ho, B.D. Iverson, Review of high-temperature central receiver designs for concentrating solar power, Renew. Sustain. Energy Rev. 29 (2014) 835-846.

[17] F. Kelbert, C. Royère, Study of a rotary kiln as a direct receiver of radiant energy, in: B.P. Gupta, H.W. Traugott (Eds.), Proceedings of the 4th International Symposium on Solar Thermal Technology - Research, Development and Applications, June 1998, pp. 327-336. Santa Fe, USA.

[18] E. Alonso, M. Romero, Review of experimental investigation on directly irradiated particles solar reactors, Renew. Sustain. Energy Rev. 41 (2015) 53-67.

[19] A. Meier, E. Bonaldi, G.M. Cella, W. Lipinski, D. Wuillemin, R. Palumbo, Design and experimental investigation of a horizontal rotary reactor for the solar thermal production of lime, in: Proc.11th SolarPACES International Symposium on Concentrated Solar Power and Chemical Energy Technologies, Zurich, Switzerland, September 4-6, 2002, pp. 365-372.

[20] A. Meier, E. Bonaldi, G.M. Cella, W. Lipinski, D. Wuillemin, R. Palumbo, Design and experimental investigation of a horizontal rotary reactor for the solar thermal production of lime, Energy (2004) 811-821.

[21] A. Meier, E. Bonaldi, G.M. Cella, W. Lipinski, D. Wuillemin, Solar chemical reactor technology for industrial production of lime, Sol. Energy 80 (2006) 1355-1362.

[22] A. Meier, N. Gremaud, A. Steinfeld, Economic evaluation of the industrial solar production of lime, Energy Convers. Manag. 46 (2005) 905-926.

[23] M. Roeb, N. Monnerie, R. Schäfer, N. Rohner, Treatment of industrial residues using concentrated sunlight, in: Ravindra K. Dhir, Moray D. Newlands, Judith E. Halliday (Eds.), Proc. of the Int. Symp. on Recycling and Reuse of Waste Materials, 9-11 Sep. 2003, pp. 315-324. Dundee, Scotland, UK.

[24] A. Navarro, I. Cañadas, J. Rodríguez, Thermal treatment of mercury mine wastes using a rotary solar kiln, Minerals 4 (2014) 37-51.
[25] M.Z. Yilmazoglu, E. Amirabedin, 3E analysis of a solar assisted rotary type coa dryer, Int. J. Renew. Energy Res. 2 (2012) 16-22.

[26] D. Bathen, M. Sonnenschein, T. Hahm, H. Schmidt-Traub, Design and construction of a solar thermal miniplant, in: World Renewable Energy Congress VI, Renewables: the Energy for the 21st Century World Renewable Energy Congress VI, 1-7 July 2000 (Brighton, UK).

[27] S.Q.S. Ahmad, R.J. Hand, C. Wieckert, Use of concentrated radiation for solar powered glass melting experiments, Sol. Energy 109 (2014) 174-182.

[28] M. Neises, S. Tescari, L. de Oliveira, M. Roeb, C. Sattler, B. Wong Solar-heated rotary kiln for thermochemical energy storage, Sol. Energy 86 (2012) 3040-3048

[29] S. Tescari, M. Neises, L. de Oliveira, M. Roeb, C. Sattler, P. Neveu, Thermal model for the optimization of a solar rotary kiln to be used as high temperature thermochemical reactor, Sol. Energy 95 (2013) 279-289.

[30] S. Tescari, C. Agrafiotis, S. Breuer, L. de Oliveira, M. Neises-von Puttkamer, M. Roeb, C. Sattler, Thermochemical solar energy storage via redox oxides: materials and reactor/heat exchanger concepts, Energy Procedia 49 (2014) 1034-1043.

[31] K.-H. Funken, M. Roeb, P. Schwarzboezl, H. Warnecke, Aluminum remelting using directly solar-heated rotary kilns, J. Sol. Energy Eng. 123 (2001) 117-124.

[32] S.O. Alexopoulos, Simulation of the Transient Operational Behaviour of Solar Heated Rotary Kilns for Aluminium Melting (Simulation des dynamischen Betriebsverhaltens von solarbeheizten Drehrohrreaktoren zum Aluminiumschmelzen) (Doctoral thesis), University of Siegen, Germany, 2003.

[33] J.P. Gorog, T.N. Adams, J.K. Brimacombe, Regenerative heat transfer in rotary kilns, Metall. Trans. 13B (1982) 153-163.

[34] F. Patisson, E. Lebas, F. Hanrot, D. Ablitzer, J.-L. Houzelot, Coal pyrolysis in a rotary kiln: part II overall model of the furnace, Metall. Mater. Trans. 31B (2000) 391-402.

[35] J.H. Lienhard IV, J.H. Lienhard V, A Heat Transfer Textbook, third ed., Prentice Hall Inc., 2001, p. 55. Eq. 2.10.

[36] K. Wilbrand, Thermal Treatment of Soil in Rotary Kiln Based Incineration Plants - Simulation and Measurement (Thermische Bodenbehandlung in Drehrohr-Verbrennungsanlagen - Simulation und Messung), Fortschrittsberichte VDI, Reihe 15, Nr. 170, Düsseldorf, Germany, 1997.

[37] J. Schöler, Overall Modell for Steam Generator Plants Using Circulating Fluidized Bed Incineration (Ein Gesamtmodell für Dampferzeugeranlagen mit zirkulierender Wirbelschichtfeuerung) (Doctoral thesis), University of Siegen, Germany, 1992.

[38] R. Viskanta, M.P. Mengüc, Radiation heat transfer in combustion systems Prog. Energy Combust. Sci. 13 (1987) 97-160.

[39] H.C. Hottel, Radiant heat transmission, in: McAdams (Ed.), Heat Transmission, McGraw-Hill, New York, 1954.

[40] R. Siegel, J.R. Howell, Thermal Radiation Heat Transfer, Wiley, New York, 1992.

[41] J.A. Stasiek, Application of the transfer configuration factors in radiation heat transfer, Int. J. Heat Mass Transfer 41 (1998) 2893-2907.

[42] P. Jochum, M. Kloas, The dynamic simulation environment smile, in G. Tsatsaronis (Ed.), Second Biennial European Conference on System Design \& Analysis, The American Society of Mechanical Engineers, 1994, pp. 53-56.

[43] M. Biersack, Design and Implementation of a Simulation Tool for dynamic Systems (Entwurf und Implementierung einer Simulationssprache für dynamische Systeme) (Diploma thesis), Technical University of Berlin, Institute of Applied Informatics, August 1994.

44] T.-H. Song, Simulation of Flow, Combustion and Heat Transfer in a Twodimensional Natural Gas-fired Industrial Furnace (Ph.D. thesis), Purdue University, USA, May 1986. 